\title{
A GABAergic Projection from the Centromedial Nuclei of the Amygdala to Ventromedial Prefrontal Cortex Modulates Reward Behavior
}

\author{
@Dong-oh Seo, ${ }^{1 *}$ @Samuel C. Funderburk, ${ }^{1,4 *}$ ๑Dionnet L. Bhatti, ${ }^{1}$ Laura E. Motard, ${ }^{1}$ Dillan Newbold, ${ }^{1}$ \\ Kasey S. Girven, ${ }^{5}$ Jordan G. McCall, ${ }^{1}$ Michael Krashes, ${ }^{4}$ Dennis R. Sparta, ${ }^{5}$ and $\odot$ Michael R. Bruchas ${ }^{1,2,3}$ \\ ${ }^{1}$ Department of Anesthesiology, Division of Basic Research, ${ }^{2}$ Department of Neuroscience, and ${ }^{3}$ Pain Center, Washington University School of Medicine, \\ St. Louis, Missouri 63110, ${ }^{4}$ Diabetes, Endocrinology and Obesity Branch, National Institutes of Diabetes and Digestive and Kidney Diseases, National \\ Institutes of Health, Bethesda, Maryland 20892, and 5 Department of Anatomy and Neurobiology, University of Maryland School of Medicine, Baltimore, \\ Maryland 21201
}

The neural circuitry underlying mammalian reward behaviors involves several distinct nuclei throughout the brain. It is widely accepted that the midbrain dopamine (DA) neurons are critical for the reward-related behaviors. Recent studies have shown that the centromedial nucleus of the amygdala (CeMA) has a distinct role in regulating reward-related behaviors. However, the CeMA and ventromedial PFC (vmPFC) interaction in reward regulation remains poorly understood. Here, we identify and dissect a GABAergic projection that originates in the CeMA and terminates in the vmPFC (VGat-Cre ${ }^{\text {CeMA-vmPFC }}$ ) using viral-vector-mediated, cell-type-specific optogenetic techniques in mice. Pathway-specific optogenetic activation of the VGat-Cre ${ }^{\text {CeMA-vmPFC }}$ circuit in awake, behaving animals produced a positive, reward-like phenotype in real-time place preference and increased locomotor activity in open-field testing. In sucrose operant conditioning, the photoactivation of these terminals increased nose-poking effort with no effect on licking behavior and robustly facilitated the extinction of operant behavior. However, photoactivation of these terminals did not induce self-stimulation in the absence of an external reward. The results described here suggest that the VGat-Cre ${ }^{\text {CeMA-vmPFC }}$ projection acts to modulate existing reward-related behaviors.

Key words: amygdala; CEA; MEA; reward; vGat; vmPFC

Significance Statement

Many studies have shown that the interactions between the centromedial nucleus of the amygdala (CeMA) and ventromedial PFC (vmPFC) have critical roles for emotional regulation. However, most studies have associated this circuit with fear and anxiety behaviors and emphasized top-down processing from vmPFC to CeMA. Here, we provide new evidence for bottom-up CeMA to vmPFC influence on reward-related behaviors. Although previous work implicated the CeMA in incentive salience, our results isolate the investigation to a specific CeMA GABAergic projection to the vmPFC. This long-range GABAergic interaction between amygdala and frontal cortex adds a new dimension to the complex regulation of reward-related behaviors.

\section{Introduction}

To survive in complex and changing environments, animals must actively attend to salient stimuli and seek out potential rewards

Received April 6, 2016; revised Aug. 29, 2016; accepted Aug. 30, 2016.

Author contributions: D.S., S.C.F., J.M., and M.R.B. designed research; D.S., S.C.F., D.L.B., L.E.M., D.N., K.S.G., and D.R.S. performed research; M.J.K. and M.R.B. contributed unpublished reagents/analytic tools; D.S., S.C.F., and D.R.S. analyzed data; D.S., S.C.F., and M.R.B. wrote the paper.

This work was supported by the National Institute on Drug Abuse-National Institutes of Health (Grant R01033396 to M.R.B.) and the National Institute on Alcohol Abuse and Alcoholism-National Institutes of Health (Grant R00021417 to D.R.S.). S.C.F. was supported by the AMGEN Biomedical Scholars Program and the Howard Hughes Medical Institute Summer Undergraduate Research Fellowship Program (SURF) program. L.E.M. was supported by the AMGEN Biomedical Scholars Program. J.G.M. was supported by the National Institutes of Health (Grant
(Hikosaka et al., 2008). In mammals, dynamic network interaction between subcortical [e.g., nucleus accumbens (NA), ventral tegmental area (VTA), and amygdala] and cortical neural struc-

F31 MH101956). We thank Lamley Lawson and Brooke Ealey for technical assistance; Kyle Parker, Adrian Gomez, and Stephanie Nygard for coordinating the experimental setup and discussions; and Joseph Dougherty, Durga Mohapatra, and Andrew Shepherd for reagents and discussions.

The authors declare no competing financial interests.

*D.S. and S.C.F. contributed equally to this work.

Correspondence should be addressed to Michael R. Bruchas, Ph.D., Department of Anesthesiology, School of Medicine, Washington University, 660 South Euclid Ave., Box 8054, St. Louis, M0 63110. E-mail: bruchasm@wustl.edu.

DOI:10.1523/JNEUROSCI.1164-16.2016

Copyright $\odot 2016$ the authors $\quad 0270-6474 / 16 / 3610831-12 \$ 15.00 / 0$ 
tures (e.g., medial PFC and orbitofrontal cortex) modulates reward value representation (Kelley and Berridge, 2002; Patton et al., 2013; Richard and Berridge, 2013; Ferenczi et al., 2016), allowing animals to respond appropriately to events. Dysregulation of this process has been implicated in the development of psychiatric disorders such as depression and drug addiction (Gorwood, 2008; Ferenczi et al., 2016).

The amygdala is an important hub for processing emotional information in both aversive and appetitive circumstances (LeDoux, 1993; Baxter and Murray, 2002; Paré et al., 2004; Lee et al., 2010; Stuber et al., 2011; Stuber et al., 2011; Li et al., 2015; Namburi et al., 2015). The amygdala is structurally diverse and mainly divided into the basolateral nuclei group (BLA) and centromedial nuclei group (CeMA) that includes the central (CeA) and medial (MeA) nucleus of the amygdala (Sah et al., 2003). Early studies suggested that the BLA encoded reward value in reward-directed behaviors (Schoenbaum et al., 1998; Baxter and Murray, 2002). The CeMA is generally considered to be a major group of output nuclei of the amygdala (LeDoux, 1993; Sah et al., 2003). However, emerging evidence supports a distinct role for the CeMA in reward-directed behaviors and food consumption (Parker et al., 2014; Robinson et al., 2014). Robinson et al. (2014) recently demonstrated that rats trained to press levers for a sucrose reward will press more frequently when sucrose is paired with concurrent stimulation of the CeA, suggesting that the CeMA amplifies external reward value.

The amygdala interacts with many neural structures across the brain, including the ventromedial PFC (vmPFC). The vmPFC also has reciprocal connectivity with the amygdala (McDonald, 1987; Jackson and Moghaddam, 2001; Baxter and Murray, 2002; Likhtik et al., 2005; Sparta et al., 2014) and has been implicated in behavioral extinction in fear-conditioning paradigms through inhibition of amygdalar circuits, but recent studies support that the vmPFC is also a key regulator of the VTA and NA, subcortical neural structures involved in goal-directed behavior and reward valuation (Jackson and Moghaddam, 2001; Peters et al., 2009; Patton et al., 2013). Previous studies have documented anatomical connections between the vmPFC and the BLA, the basomedial nucleus of amygdala, and the intercalated cells, supporting a top-down control mechanism (Peters et al., 2009; Cho et al., 2013; Adhikari et al., 2015). However, direct connections between the CeMA and vmPFC supporting a bottom-up control mechanism and its function has not been described.

Here, we describe a novel GABAergic projection from the CeMA to the vmPFC using cell-type-specific optogenetic techniques. Using adeno-associated virus (AAV)-mediated gene transfer to transduce the CeMA with the light-gated ion channel, channelrhodopsin-2 (AAV5-EF1 $\alpha$-DIO-ChR2-eYFP), we selectively targeted the inhibitory projection neurons of the CeA and dorsal part of MeA (CeMA) using VGat mice (VGat ${ }^{\text {CeMA }}$-Cre) and stimulated the vmPFC region to isolate the GABAergic

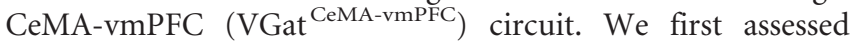
whether this VGat ${ }^{\text {CeMA-vmPFC }}$ circuit is involved in modulating emotional valence and general locomotor activity. We then explored its function in reward-seeking behavior using a sucrose reward operant conditioning paradigm. Our study revealed that the inhibitory projection from the CeMA to the vmPFC is specifically involved in the amplification of an external reward value, as well as modulation of extinction in sucrose operant conditioning.

\section{Materials and Methods}

Subjects. Group-housed adult (25-35 g) male VGat-IRES-Cre mice (RRID:IMSR_JAX:016962) and Cre(-) littermate controls were used for projection mapping and all in vivo experiments (Vong et al., 2011). Mice were given access to food pellets and water ad libitum and maintained on a 12:12 h light/dark cycle (lights on at 7:00 A.M.). All experimental procedures were approved by the Animal Care and Use Committee of Washington University and conformed to National Institutes of Health guidelines.

Surgical procedures for viral injection and fiber-optic placement. All surgeries were performed under $4 \%$ isoflurane anesthesia (Piramal Healthcare). For initial projection mapping, adult male mice were injected unilaterally with $500 \mathrm{nl}$ of AAV5-EF1 $\alpha$-DIO-eYFP virus (WUSTL Hope Center Viral Core) into the CeA (AP: $-1.35 \mathrm{~mm}$, ML: $-2.75 \mathrm{~mm}, \mathrm{DV}$ : $-4.5 \mathrm{~mm}$ ), and CTB into vmPFC (AP: $+1.95 \mathrm{~mm}, \mathrm{ML}:+0.25 \mathrm{~mm}$, DV: -2.80 ). For behavior and physiology experiments, adult male mice were injected unilaterally with $500 \mathrm{nl}$ of AAV5-EF1 $\alpha$-DIO-ChR2-eYFP virus (WUSTL Hope Center Viral Core) into the CeA (AP: $-1.35 \mathrm{~mm}$, ML: $-2.75 \mathrm{~mm}$, DV: $-4.5 \mathrm{~mm}$ ) (Cai et al., 2014; McCall et al., 2015). The CeA was targeted carefully and viral volumes were limited accordingly, although there was expression in the MeA at times due to the use of a vGAT-IRE-cre driver mouse; therefore, the target is referred to as centromedial nuclei herein to avoid confusion and to relay information for future studies. Four to 5 weeks after virus injection, fiber-optic ferrules were implanted chronically above the infralimbic PFC (AP: $+1.78 \mathrm{~mm}$, ML: $-0.3 \mathrm{~mm}, \mathrm{DV}:-2.25 \mathrm{~mm}$ ) and dental cement (Lang Dental) was applied to hold the ferrules in place (Sparta et al., 2012). Mice were allowed to recover for at least 6 weeks after infusion of virus before further behavioral testing or perfusion for projection mapping to ensure optimal viral expression.

Patch-clamp electrophysiology. Brain slice preparation and general methods for patch-clamp electrophysiology were conducted as described previously (Jennings et al., 2013). To examine CeMA postsynaptic currents evoked by optical stimulation of GABA neurons, $200 \mu \mathrm{m}$ coronal slices containing the $\mathrm{mPFC}$ were prepared from mice expressing ChR2eYFP in CeA GABA neurons. For whole-cell voltage-clamp recordings of IPSCs from mPFC putative pyramidal neurons, electrodes $(2-4 \mathrm{M} \Omega$ electrode resistance) contained the following (in $\mathrm{mm}$ ): 130 cesium chloride, 10 HEPES, 1 EGTA, $2 \mathrm{Mg}$-ATP, and 0.2 Na-GTP, pH 7.2-7.4, 275-285 mOsm. Photostimulation (5 ms pulses of 1-2 mW, $473 \mathrm{~nm}$ light delivery via LED through a $40 \times$ microscope objective) was used to stimulate CeA GABA terminals expressing ChR2-eYFP in the mPFC. If mPFC cells were light responsive, then $10 \mu \mathrm{m}$ gabazine was applied. All cells were held at $-70 \mathrm{mV}$.

Real-time place preference (RTPP). Mice were placed into a custommade black acrylic two-chambered box $(52.5 \times 25.5 \times 25.5 \mathrm{~cm})$ and allowed to explore each of two chambers for $30 \mathrm{~min}$. Using an Ethovision hardware controller (Noldus Information Technologies) connected to a master 9 functional generator, light stimulation $(473 \mathrm{~nm}, \sim 10 \mathrm{~mW})$ at 20,30 , or $60 \mathrm{~Hz}$ (10 ms pulse width) was delivered through fiber-optic implants during the duration of their time spent in the light stimulation side of the chamber. Mice received no light stimulation on the "no stimulation" side. The experimental animals were counterbalanced for both group and stimulation side. Preference scores in each experiment were determined by computing the percentage of time spent in the "light stimulation" side out of the total explored time during the tests. All behavioral data, including traveled distance and time, were collected and analyzed using Ethovision version 9.5 software (Noldus Information Technologies, RRID:SCR_000441) with a digital camera (ZR900; Canon) mounted above. Mice that did not cross the threshold between the two chambers were excluded from analysis.

Open-field test $(O F T)$. Mice were placed into a custom-made white box $(50 \mathrm{~cm} \times 50 \mathrm{~cm})$ within a sound-attenuated room maintained at $\sim 23^{\circ} \mathrm{C}$. Lighting was measured and stabilized at $\sim 25$ lux. Mice were allowed to explore the entire chamber freely for $30 \mathrm{~min}$. Using the Ethovision hardware controller connected to a master 9 functional generator, light stimulation ( $473 \mathrm{~nm}, \sim 10 \mathrm{~mW}, 10 \mathrm{~ms}$ pulse width) at $20 \mathrm{~Hz}$ was delivered through fiber-optic implants for the duration of the trial. Time spent in the center of the open field was used as a measure of anxiolysis. All behavioral tracking data were collected and analyzed using Ethovision software with the digital camera mounted above. 
Sucrose operant conditioning. All tests took place in mouse operant chambers $(17.8 \mathrm{~cm} \times 15.2 \mathrm{~cm} \times 18.4 \mathrm{~cm}$; Med Associates $)$. A rotating optical commutator (Doric) was located on the top of the operant chamber and connected to a $473 \mathrm{~nm}$ diode-pumped solid-state laser (OEM Laser Systems; see Fig. 3B). Fibers were connected to the implants on the mouse for every training session. The conditioning chamber light was turned on during every training session. Laser power was adjusted to obtain $\sim 10 \mathrm{~mW}$ transmittance into the brain. Mice were initially food deprived to $90 \%$ body weight and habituated to operant chambers and a lickometer program for 20 trials of 20 s sipper release with variable interval for $60 \mathrm{~min}$. During the $20 \mathrm{~s}$ sipper release period, an orange-colored cue light turned on above the sipper. Training continued until each mouse produced at least 300 licks in a session.

FR1 and extinction. Mice were trained to nose poke in a MED Associates operant box with two nose-poke portals available, "active" and "inactive." Successful nose pokes on the active nose poker rewarded the mouse with $20 \mathrm{~s}$ access to a sipper providing 10\% sucrose solution. Operant responses on active portal were reinforced on a fixed ratio 1 (FR1) schedule. Nose poking to the active portal during the $20 \mathrm{~s}$ reward period and to the inactive portal produced no consequences or rewards. This procedure was repeated for $8 \mathrm{~d}$ for animals to get criteria (reinforcers $>25$, active lever presses $>70 \%$, in the last 3 consecutive days of the FR1 training). For extinction, the experimental setup was the same except that the active portal was disabled and light stimulation $(20 \mathrm{~Hz}, \sim 10$ $\mathrm{mW}, 10 \mathrm{~ms}$ pulse width) was delivered throughout the $60 \mathrm{~min}$ session.

Self-stimulation. Successful nose pokes on the active portal were rewarded with 20 s of light stimulation $(20 \mathrm{~Hz}, \sim 10 \mathrm{~mW})$ with the cue light. An inactive nose poke resulted in neither stimulation nor cue light. This procedure was repeated for $2 \mathrm{~d}$.

FR3 + light stimulation. Three successive nose pokes (FR3) to the active portal rewarded the mouse with $20 \mathrm{~s}$ access to a sipper that delivered 10\% sucrose solution with concurrent light-stimulation $(20 \mathrm{~Hz})$.

Immunohistochemistry. After the conclusion of behavioral testing, mice were anesthetized with sodium pentobarbital and transcardially perfused with ice-cold PBS, followed by $4 \%$ phosphate-buffered paraformaldehyde. Brains were removed, postfixed overnight in 4\% paraformaldehyde, and then saturated in 30\% phosphate-buffered sucrose. Next, 30 $\mu \mathrm{m}$ sections were cut, washed in $0.3 \%$ Triton $\mathrm{X}-100 / 5 \%$ normal goat serum in 0.1 M PBS, stained with fluorescent Nissl stain (1:400 Neurotrace; Invitrogen) for $1 \mathrm{~h}$, and mounted onto glass slides with Vectashield (Vector Laboratories). For immunofluorescence labeling, sections were incubated in blocking solution (PBS with 5\% normal goat serum and $0.3 \%$ Triton $\mathrm{X}-100$ ) for $1 \mathrm{~h}$ with gentle agitation before incubation with the following primary antibodies: rabbit anti-GAD67 (1:1000) and anti-GAD65 (1:1000, Millipore Cat\# AB1511, RRID: AB_11210186). Sections were incubated with primary antibodies at room temperature overnight and rinsed for $5 \mathrm{~min}$ in 3 changes of PBS. Secondary antibodies (Alexa Fluor 568-conjugated goat anti-rabbit, Invitrogen Cat\# A1 1011, RRID: AB_2534078) were diluted in PBS (secondary antibodies at 1:1000) with 5\% normal goat serum and $0.3 \%$ Triton $\mathrm{X}-100$. Sections were incubated for $2 \mathrm{~h}$ at room temperature with gentle agitation and then rinsed in PBS, mounted, and coverslipped.

Viral ChR2 expression was verified using fluorescence (Olympus) and confocal (Leica Microsystems) microscopy. Images were produced with $10 \times, 20 \times, 63 \times, 100 \times$ objective and analyzed using Image software $(\mathrm{NIH})$ and Leica Application Suite Advanced Fluorescence software. Mice that did not show targeted expression were excluded. Fluorescence intensities are reported separately for the vmPFC, CeA, and dorsal part of medial nucleus of amygdala (dMeA). The vmPFC axonal terminal fluorescence was measured $\sim 1.70$ to $1.98 \mathrm{~mm}$ relative to bregma and comprised a 3-section series (Paxinos, 2001). CeA fluorescence was measured -0.90 to $-1.80 \mathrm{~mm}$ and comprised a 3 -section series.

Statistical analysis. All data are expressed as mean \pm SEM. Behavioral data were analyzed with JMP12 Pro (SAS Institute, RRID:SCR_014242). Student's $t$ test and one-way or two-way ANOVAs were used to analyze between-subjects designs. Repeated-measures designs were analyzed using a mixed-effects restricted maximum likelihood (REML) model. Least significant difference was used for post hoc pairwise comparisons. The null hypothesis was rejected at the $p<0.05$ level. Statistical significance was taken as ${ }^{*} p<0.05,{ }^{* *} p<0.01,{ }^{* *} p<0.001$.

\section{Results}

\section{Identification of a GABAergic projection from the CeMA to the vmPFC}

The CeMA, which is typically associated with fear and anxiety behaviors, has recently been identified as a mediator of incentive motivation (Robinson et al., 2014). However, the incentive motivation-related downstream circuit is relatively less investigated compared with the circuits in fear and anxiety. The CeMA contains large populations of GABAergic neurons (Davis et al., 1994; Sah et al., 2003). Therefore, we explored the GABAergic projection from CeMA using viral vector-mediated, cell-typespecific florescence tracing techniques.

We expressed the genetically encoded light-sensitive cation channel (AAV5-EF1 $\alpha$-DIO-ChR2) in the CeA-vmPFC pathway under the control of mouse vesicular GABA transporter (VGat) promoter, which is expressed in inhibitory neurons (GABAergic and glycinergic neurons; Fig. $1 A$ ). Viral tracing revealed a vgat ${ }^{+}$ nerve bundle that originated in the CeA (Fig. 1B) and terminated in the vmPFC (Fig. 1C). In the CeA, the virus expressed widely throughout anterior-posterior axis and almost covered the entire CeA area, but was not seen in the BLA. This is consistent with the report that this transgenic mouse line has relatively low level of Cre activity in the BLA (Vong et al., 2011). The ChR2 virus also sparsely spread to the dorsal part of the MeA (Fig. 1B); therefore, for accuracy, we refer to our targeting here as CeMA. This bundle exited the CeA through a known pathway: the stria terminalis (images are not shown). Our viral tracing, however, revealed a subpopulation of axons that continued anteriorly to the frontal cortex, terminating primarily in the vmPFC including infralimbic PFC (Fig. 1C), medial orbitofrontal cortex, and dorsal peduncle. In particular, relatively dense fluorescence expression was observed around the medial wall of the vmPFC along the midline axis. The prelimbic PFC shows a relatively low level of projections. These fluorescently labeled CeMA-vmPFC terminals were coexpressed with GAD65 + 67 immunoexpression, which suggests that these terminals are long-range inhibitory terminals originating from the CeMA (Fig. 1E). For control purposes, we injected the same type of virus in VGlut-Cre mice, which express Cre in glutamatergic neurons (Vong et al., 2011). Whereas a known VGlut $^{+}$projection from the BLA to the vmPFC and surrounding regions was identified, there was limited expression of glutamatergic cells in the CeA (images not shown).

To examine the functional connectivity between CeMA GABA projection neurons and vmPFC neurons, whole-cell recordings from vmPFC neurons revealed that photostimulation of ChR2-containing terminals originating from CeMA GABA neurons produced IPSCs and formed functional synapses on neurons within the vmPFC (Fig. $1 F-I$ ). In addition, we found that application of gabazine completely blocked the eIPSC, indicating that this projection is GABAergic (Fig. $1 H, I ; t_{(4)}=3.83, p=$ 0.019 ). We also found that the latency to a response was $1.96 \mathrm{~ms}$ upon onset of light stimulation. Furthermore, the time to peak of the eIPSC was $4.78 \mathrm{~ms}$, suggesting that this projection is monosynaptic. However, we cannot rule out a polysynaptic connection. Together, these data suggest that our methods allowed for preferential targeting and manipulation of CeMA GABAergic fibers within the vmPFC. 
A
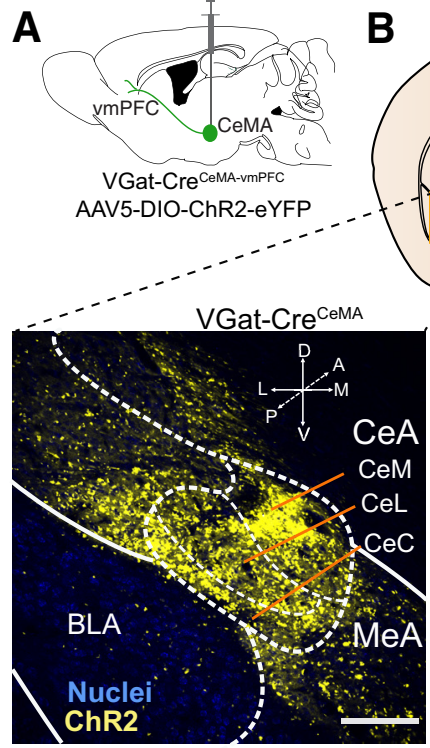

$\mathbf{F}$

F Patch-clamp slice electrophysiology

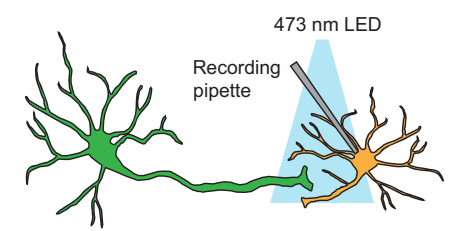

CeMA GABA neuron (ChR2) PFC neuron (no ChR2)

B

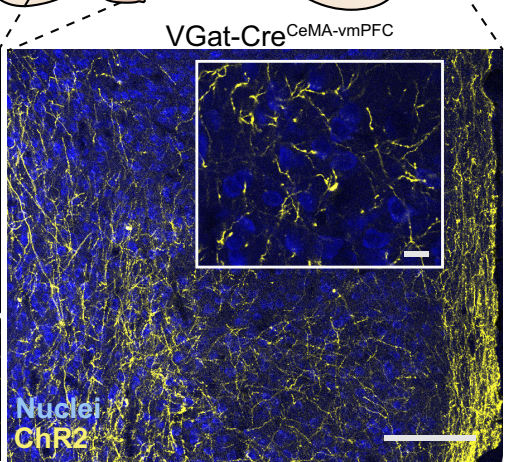

G

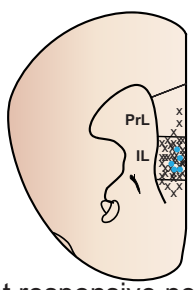

- Light responsive neuron

$x$ Non-light responsive neuron
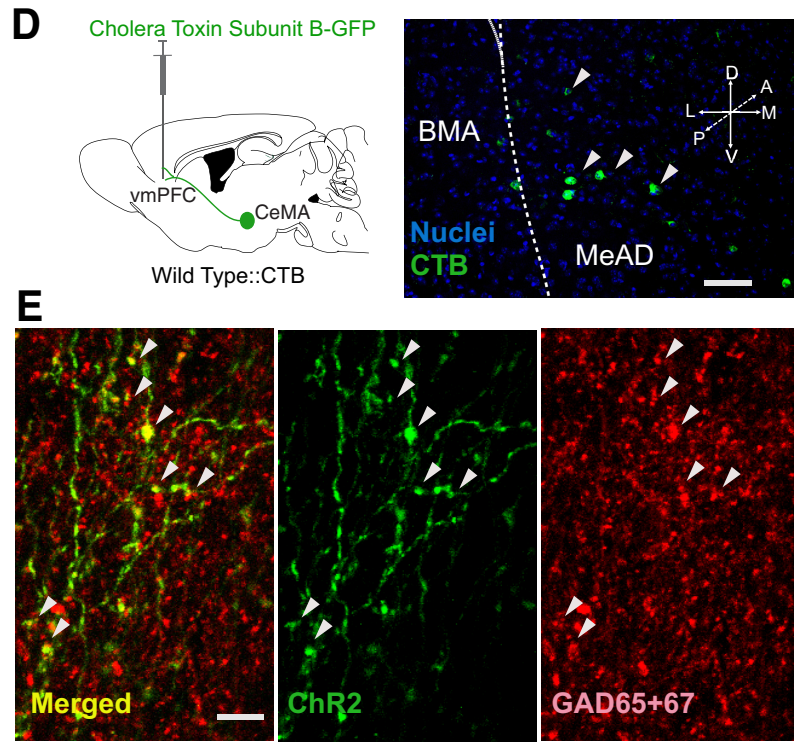

H
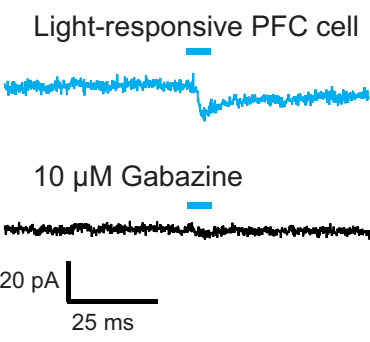

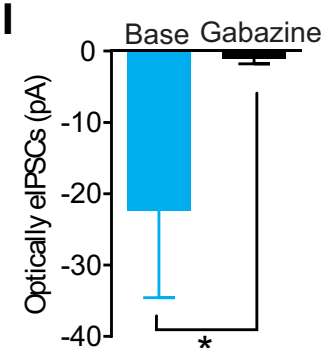

Figure 1. GABAergic projections from the CeMA to the vmPFC. $\boldsymbol{A}$, Diagram showing viral delivery into the CeMA of VGat-IRES-cre mouse. $\boldsymbol{B}$, Representative confocal image of ChR2-eYFP expression in the CeMA. C, Confocal image showing representative ChR2-eYFP fiber expression in the vmPFC of VGat-IRES-cre mice. Inset shows the high-magnification image. $\boldsymbol{D}$, Diagram showing CTB delivery into the vmPFC of a wild-type mouse and CTB expression in the CeMA. $E$, Representative images of GAD65 +67 immunohistochemistry of the eYFP expressing terminals in the vmPFC. The eYFP-expressing terminals coexpresses with GAD65 + 67.F, Schematic diagram depicting combined patch-clamp electrophysiological and optogenetic manipulations in the vmPFC. G, vmPFC patching map. $\boldsymbol{H}$, Example trace of a light-responsive vmPFC neuron (top) and a light-responsive vmPFC neuron treated with gabazine (bottom). $\boldsymbol{I}$, photostimulation of ChR2-containing terminals originating from CeMA GABA neurons produced IPSCS. ${ }^{*} p<0.05$. CeL/CeM/CeC, lateral/medial/capsular subdivisions of the central nucleus of amygdala; IL/PrL, impralimbic/prelimbic PFC. Scale bars: $\boldsymbol{B}, 250 \mu \mathrm{m} ; \boldsymbol{C}, 100$ and $10 \mu \mathrm{m}$ (inset); $\boldsymbol{D}, 5 \mu \mathrm{m}$.

\section{VGat-Cre ${ }^{\text {CeMA-vmPFC }}$ terminal photoactivation facilitates RTPP and increases locomotion}

Earlier studies have shown that the amygdala and PFC play important roles in modulating multiple behavioral paradigms with motivational valence components such as Pavlovian fear conditioning and drug-based operant conditioning (LeDoux, 1993; Baxter and Murray, 2002; Peters et al., 2009; Nieh et al., 2013). First, we assessed whether the CeMA to vmPFC GABAergic projections (VGat ${ }^{\mathrm{CeMA}-\mathrm{vmPFC}}$ ) are involved in modulating valence state using RTPP. Mice were placed into a black acrylic twochambered box for RTPP tests as described previously (AlHasani et al., 2015; McCall et al., 2015; Siuda et al., 2015). To determine optimal stimulation parameters, we performed a frequency-response RTPP. Photostimulation was delivered in a closed loop during travel into the light-paired side at 20,30, and $60 \mathrm{~Hz}$ (10 ms pulse width) each experimental day (Fig. $2 A, B)$.

In this experiment, the VGat ${ }^{\mathrm{CeMA}-v m P F C}$ ::ChR2 mice spent significantly more time on the side paired with light-stimulation than control mice (VGat::Cre- littermates) under all three different stimulation conditions $(20 \mathrm{~Hz}, 30 \mathrm{~Hz}$, and $60 \mathrm{~Hz})$, indicating a preference for light stimulation of the CeMA-vmPFC terminals (Fig. 2C,D; REML: group, $F_{(1,23.26)}=12.41, p=0.002$; group $\times$ frequency, $F_{(3,39.35)}=3.65, p=0.020$; the degree of freedom is adjusted; post hoc, control vs ChR2 at $0 \mathrm{~Hz}, p=0.26$, at $20 \mathrm{~Hz}, p=0.03$; at 30 and
$60 \mathrm{~Hz}, p<0.003)$. Further analysis of the $20 \mathrm{~Hz}$ light-stimulation data, similar to recent CeA-optogenetic studies with functional relevance to reward-related behavior (Robinson et al., 2014), showed a significant preference for the light-paired side (Fig. $2 C, E ; t_{(21)}=3.06$, $p=0.005)$ without changes in total distance traveled (Fig. $2 F ; t_{(21)}=$ $0.63, p=0.531$ ).

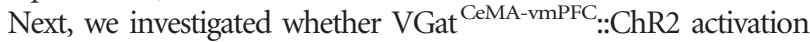
drives generalized changes in reward valence and general locomotor activity. The same group of mice was tested in open field $2 \mathrm{~d}$ after RTPP tests. Upon placement into an empty white box as described previously (Siuda et al., 2015), the VGat ${ }^{\mathrm{CeMA}-\mathrm{vmPFC}}$ ::ChR2 mice traveled significantly more compared with wild-type control mice (Fig. $2 G, H ; t_{(12)}=$ $2.330, p=0.0381)$ at $20 \mathrm{~Hz}$; however, there were no significant changes in the distance traveled in the center of the open field (Fig. $2{ }^{\prime} t_{(12)}=0.95$, $p=0.358$, n.s.), indicating a lack of effect on anxiety-related behaviors. Together, these results suggest that this GABAergic projection from CeMA to vmPFC can cause reward-like behaviors and affect general locomotion, but on its own, it does not affecty general anxiety-like behavior.

VGat-Cre ${ }^{\mathrm{CeMA}-\mathrm{vmPFC}}:$ :ChR2 terminal light activation is not sufficient to induce self-stimulation

In the above experiments, activation of the GABAergic projection from CeMA to vmPFC drove behaviors with positive motivational 
A

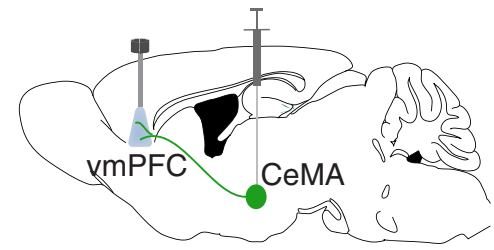

VGat-Cre ${ }^{\text {CeMA-vmPFC.:AAV5-DIO-ChR2 }}$

C
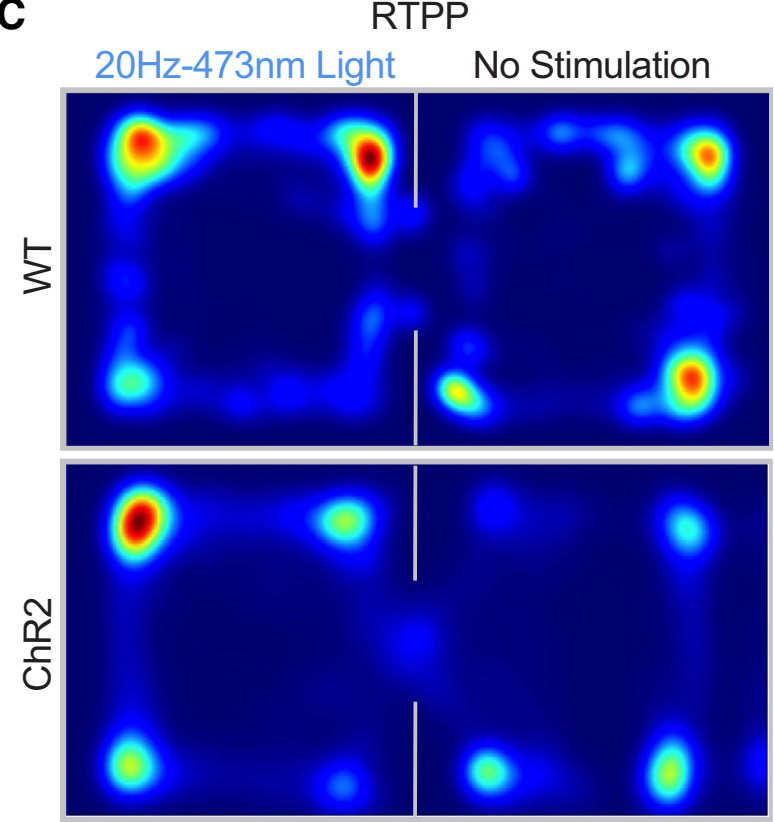

OFT

G

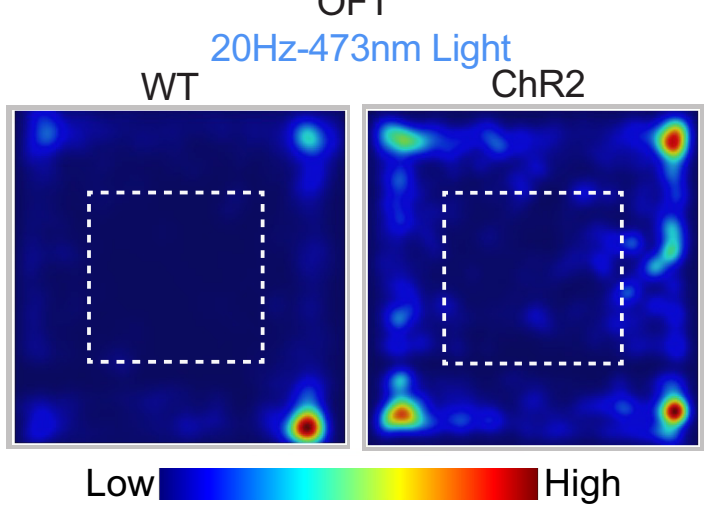

B Weeks 0
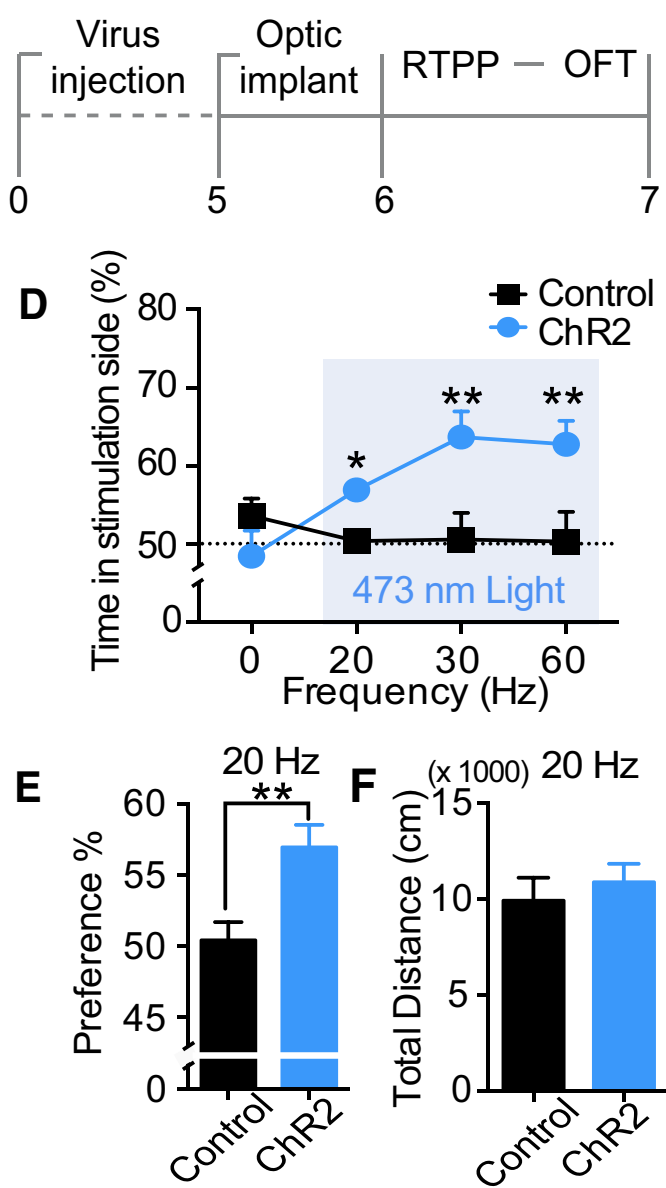

H

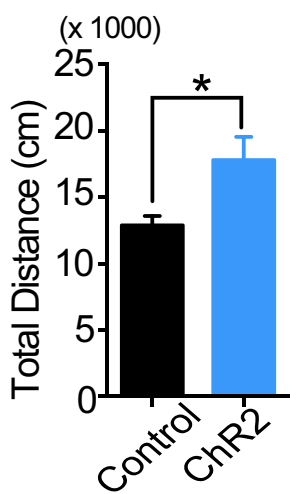

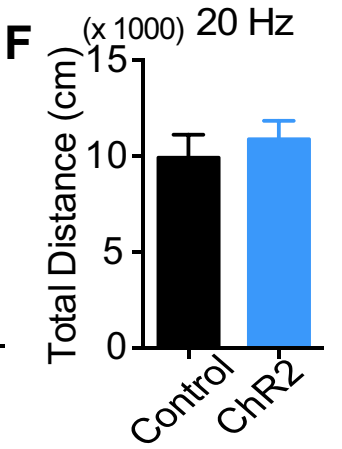

I

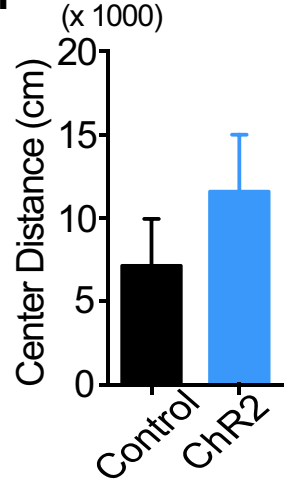

Figure 2. VGat-Cre ${ }^{\text {CeMA-vmPFC }}$ terminal photoactivation facilitates RTPP and increases locomotion. A, Diagram showing viral delivery of AAV5-EF1 $\alpha$-DI0-ChR2-eYFP into the CeA and fiber-optic

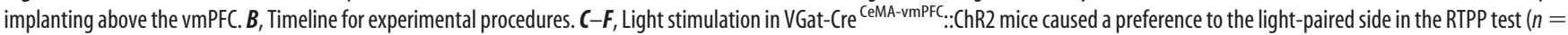
$5-13$ /group). C, Occupancy plots for representative individual mice. $\boldsymbol{D}, \boldsymbol{E}$, Various frequency responses and independent analysis at $20 \mathrm{~Hz}(\boldsymbol{E}) . \boldsymbol{F}$, There were no differences in distance traveled in the RTPP. $\mathbf{G}-\boldsymbol{I}$, Light stimulation in VGat-Cre ${ }^{\mathrm{CeMA}-\mathrm{vmPF} . . .}$.ChR2 mice caused increased exploration behavior in the OFT. $\boldsymbol{G}$, Occupancy plots for representative individual mice. $\boldsymbol{H}, \boldsymbol{I}$,

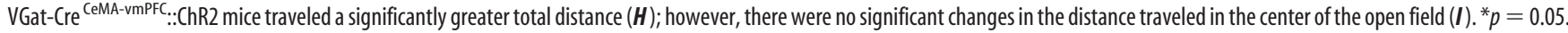

valence and real-time preference. To further assess whether VGat ${ }^{\text {CeMA-vmPFC }}$ photoactivation itself was an independent reward, we used an operant self-stimulation paradigm in which mice could self-stimulate with $20 \mathrm{~Hz}$ (20 s) photoactivation by nose poke (Fig. $3 A, B)$. Importantly, these mice were pretrained in a sucrose operant conditioning on an FR1 schedule with 10\% sucrose solution delivery to the sipper before this self-stimulation training

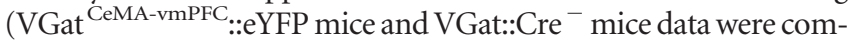
bined into a single control group). In the FR1 training, all groups of mice showed similar level of nose-poking performance for a sucrose reward, indicating that both groups of mice were able to perform normal nose-poking behaviors (see Fig. $6 C, D$ ). To avoid the compounding effect with the sucrose-associated nose-poke portal, the previously "inactive" nose-poke portals were used as the "active" reinforcing nose-poke portal in this experiment (Fig. 3B). Results showed that the VGat ${ }^{\mathrm{CeMA}-\mathrm{vmPFC}}:$ :ChR2 light stimulation failed to produce significant self-stimulation (Fig. $3 C, D$; Fs $>1$, n.s.). These

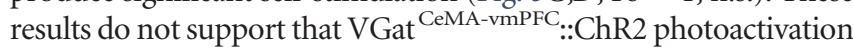


has positively reinforcing properties in the operant setup and suggest that VGat CeMA-vmPFC::ChR2 photoactivation does not affect intrinsic motivational states.

\section{VGat-Cre ${ }^{\text {CeMA-vmPFC }: \text { ChR2 terminal }}$ activation modulates external reward value}

The self-stimulation experiment did not support that VGat ${ }^{\text {CeMA-vmPFC }}$ activation was an independent reward or reinforcer, but to test whether the VGat CeMA-vmPFC projection may be involved in modulating external reward value rather than modulating intrinsic motivation, as previously reported for somatic CeA stimulation (i.e., amplification of the intensity of incentive motivation; Robinson et al., 2014), we designed a behavioral experiment to test whether VGat CeMA-vmPFC activation amplifies the reward value of sucrose in an operant conditioning paradigm. Mice were trained on FR1 sucrose operant conditioning again to establish that their basal response levels to a sucrose reward was equivalent between both groups (Fig. 4A). In addition, a separate cohort of animals was trained on FR1 without exposure to any other behavioral training such as extinction and self-stimulation.

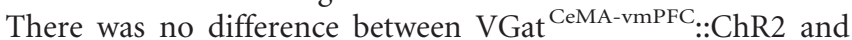
control groups in the number of rewards taken (Fig. $4 C ; t_{(30)}=$ $-0.76, p=0.451$ ) or active nose pokes (Fig. $4 F ; t_{(30)}=-0.82$, $p=0.414$ ) on day 1 of the FR1 schedule. Starting on day 2, mice were trained on an FR3 schedule for $3 \mathrm{~d}$ with concurrent photostimulation in the vmPFC (Fig. 4B). VGat CeMA-vmPFC::ChR2 mice showed a significantly higher number of rewards received (Fig. 4D; REML: group, $F_{(1,30.13)}=6.11, p=0.019$; day, $F_{(1,59.29)}=3.10, p=0.052$; group $\times$ frequency, $F_{(1,59.29)}=0.71$, $p=0.495$; degree of freedom is adjusted) and active nose pokes (Fig. 4G; REML: group, $F_{(1,30.15)}=6.29, p=0.017$; day, $F_{(1,59.34)}=2.60, p=0.08$; group $\times$ frequency, $F_{(1,59.34)}=0.79$, $p=0.46$; degree of freedom is adjusted). On the fifth day, to confirm that the increased performance was truly due to the activation of the VGat ${ }^{\mathrm{CeMA}-\mathrm{vmPFC}}$ projection, mice were tested once more on an FR3 schedule without photostimulation. There were still significant differences between the two groups in the number of rewards (Fig. $4 E ; t_{(30)}=-2.43, p=0.02$ ) or active nose pokes (Fig. $4 H ; t_{(30)}=-2.40, p=0.02$ ), suggesting that activation of this projection was sufficient to produce positive reward learning. However, even though there were significant increases in nosepoke responses in the VGat ${ }^{\mathrm{CeMA}-\mathrm{vmPFC}}:$ :ChR2 mice on the fourth day (FR3 + light), the response distribution showed relatively large variability (Fig. 4G,I). This variability in the performance of the VGat ${ }^{\mathrm{CeMA}-\mathrm{vmPFC}}:: \mathrm{ChR} 2$ mice on the fourth day precludes a clear answer to whether increased responses in the VGat ${ }^{\mathrm{CeMA}-\mathrm{vmPFC}}:$ :ChR2 mice were due to transient motivational changes or a persistent behavioral change through the modulation of external reward value. Therefore, the VGat ${ }^{\mathrm{CeMA}-\mathrm{vmPFC}}$ ::ChR2 mice were divided into two groups at the median value of the "day 4: FR3 + light" active nose pokes (median $=167$ ). The

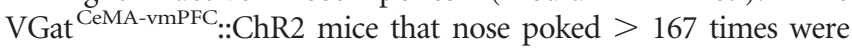
categorized as the "amplified" group and the mice that nose poked $<$ 167 times were categorized as the "nonamplified" group (Fig. 4I).
Further analysis comparing these three groups (amplified, nonamplified, and control) using REML analysis revealed that the amplified group of mice nose poked significantly more than other groups on the fourth day, but the increased number of nose pokes in the amplified group of mice was significantly decreased to the nonamplified response and control level on the FR3 training day (FR3 + no light; Fig. 4J; REML; responder, $F_{(2,29)}=11.44, p<0.001$; session, $F_{(1,29)}=3.58, p=0.068$; group $\times$ session, $F_{(2,29)}=10.32, p<0.001$; Tukey, light vs no light in the amplified group, $p=0.001$, amplified vs nonamplified; control on the FR3 + light, $p<0.001)$. We could not find clear differences in the targeting area of the fiber-optic (Fig. $4 K$ ), eYFP axonal fiber expression in the vmPFC (Fig. $4 L$ : vmPFC, $t_{(13)}=0.20, p=0.844$ ), eYFP expression in the CeA (Fig. 4L: CeA, $F_{(1,11)}=0.93, p=0.355$; group $\times$ region, $\left.F_{(2,22)}=1.64, p=0.215\right)$, or eYFP expression in the MeA (Fig. $4 L$ : MeA, $F_{(1,12)}=1.06, p=$ 0.322 ; group $\times$ region, $\left.F_{(2,24)}=2.74, p=0.085\right)$ between the amplified and nonamplified groups. However, there was a trending correlation between fluorescence intensity of the vmPFC and performance (FR3 + light active nose poke; Fig. $4 M ; p=0.066$ ), but not in the comparison with the CeA or MeA fluorescence intensity (data are not shown; CeA, $p=0.853$; MeA, $p=0.963$ ). Together, these results suggest that activation of the VGat ${ }^{\mathrm{CeMA}-\mathrm{vmPFC}}$ projection is sufficient to modulate external reward value.

VGat ${ }^{\text {CeMA-vmPFC }}$ activation does not alter reactivity to sucrose Studies have shown that midbrain doapminergic systems are involved in reward consumption. For example, activation of GABAergic neurons in the VTA decreased the lick rate in sucrosereward-seeking tasks (van Zessen et al., 2012). In addition, previous reports suggested that the CeA is involved in unconditioned food consumption behaviors (Gosnell, 1988; Cai et al., 2014). To assess whether activation of

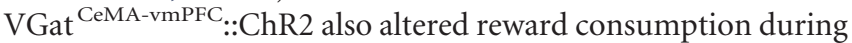
the sipper release periods in the sucrose operant conditioning test, we quantified the number of licks during the FR3 + light (day 4) and FR3 + no light (day 5). There was a trend that 
A

A Virus Optic Food \begin{tabular}{l|l|l|l|} 
& & & \\
Weeks 0 & 4 & 5 & 6
\end{tabular}

B

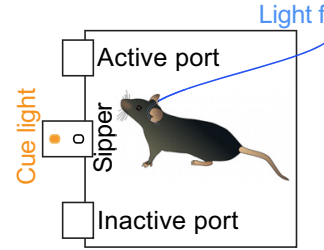

C

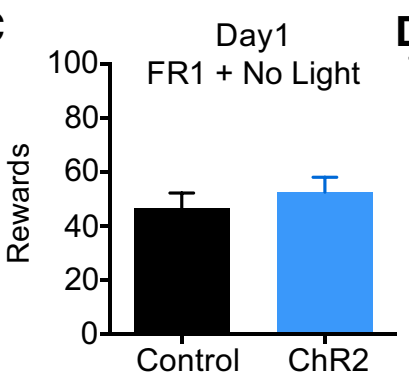

F

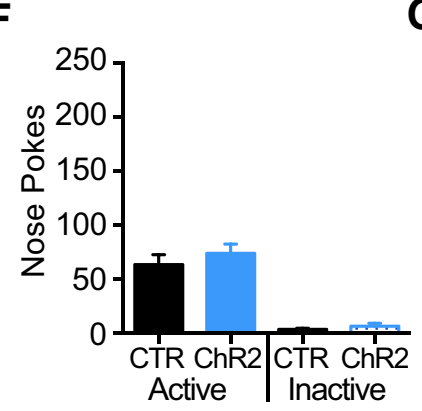

D

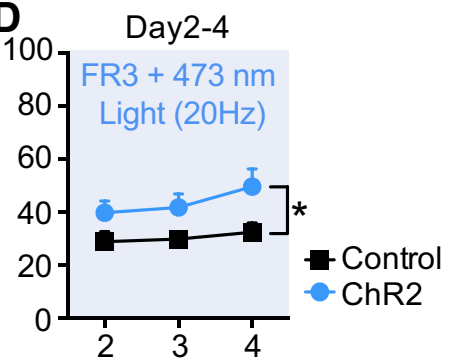

G

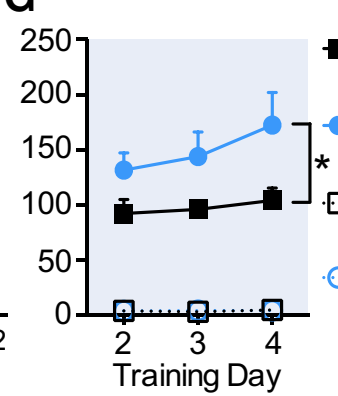

Active-

Control

Active-

ChR2

Control

ChR2

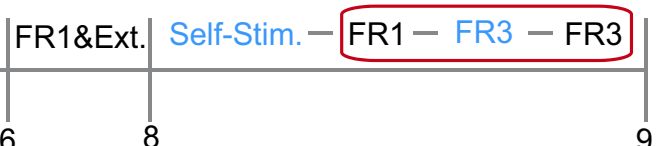

Active portal (FR3)
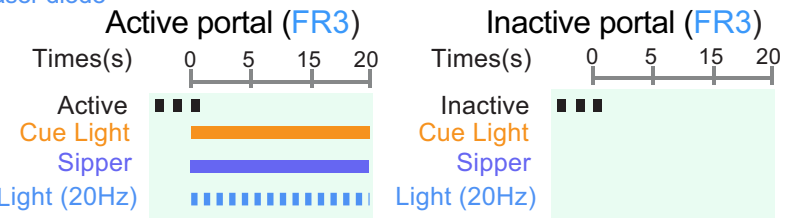

E

$\mathrm{H}$

Inactive-

Inactive-
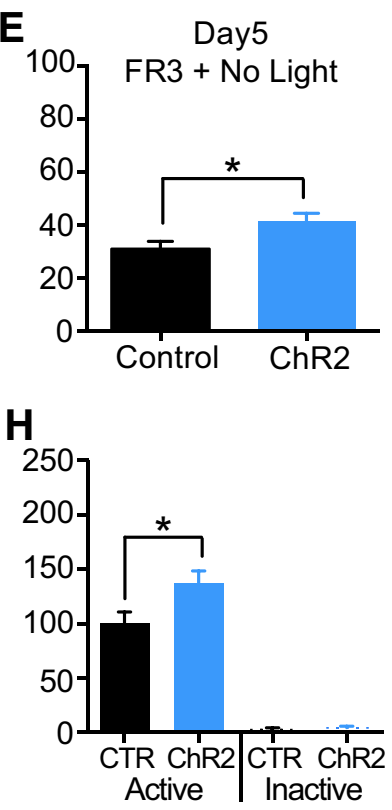

Inactive portal (FR3)

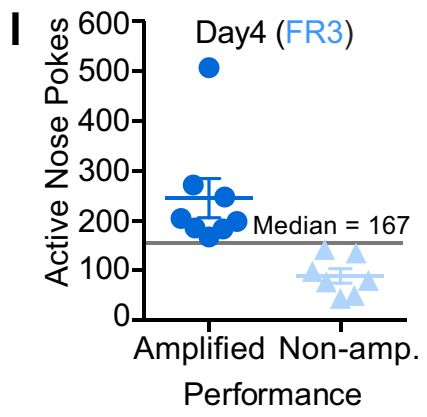

L

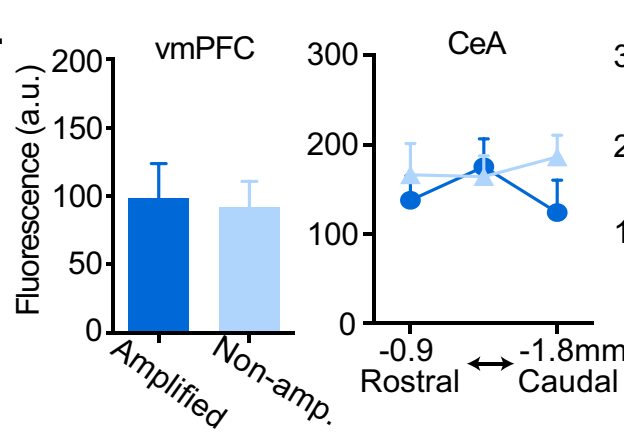

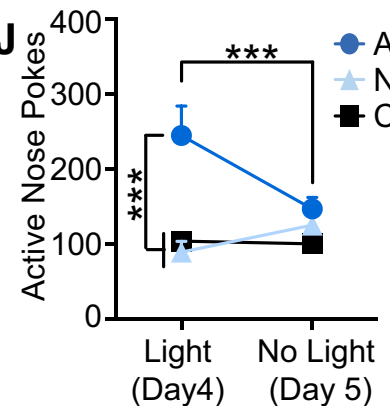

Sessions
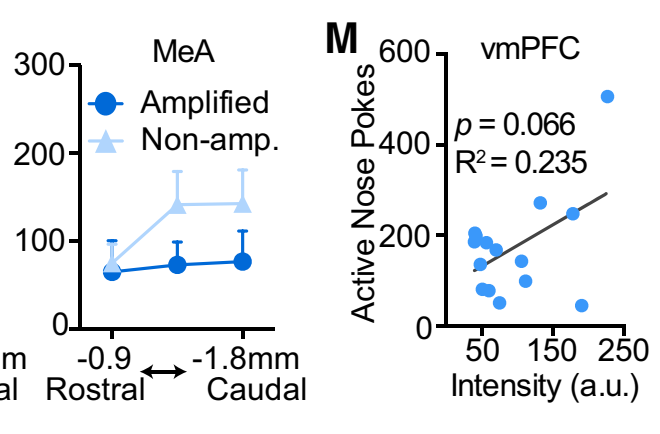

Figure 4. VGat-Cre CeMA-vmPFC.:.ChR2 terminal activation modulates external reward value. $A$, Timeline of experimental procedures. Red box: FR1 (day 1), FR3 + light (days $2-4)$, FR3 + no-light (day 5). Blue text represents behavioral tests performed with light stimulation. $\boldsymbol{B}$, Configuration of FR3 training with sucrose reward and light stimulation (day 2,3 , 4 ). Day 5 was identical to days 2-4 except no light stimulation was delivered (not shown in figure). $\boldsymbol{C}-\boldsymbol{H}$, Two groups ( $n=15-17 /$ group) showing equivalent performance in the number of rewards earned ( $\boldsymbol{C}$ ) and active nose pokes $(\boldsymbol{F})$ on day 1 of the FR1 schedule. Starting on day 2, animals were trained on an FR3 schedule for 3 d with concurrent light stimulation. The VGat ${ }^{C e M A-v m P F C .: C h R 2 ~ m i c e ~ s h o w e d ~ s i g n i f i c a n t l y ~}$ more rewards $(\boldsymbol{D})$ and active nose pokes $(\boldsymbol{G})$. The facilitated reward response was still detected in the FR3 training without light stimulation on the following day $(\boldsymbol{E}, \boldsymbol{H})$. $\boldsymbol{I}$, Distribution of performance

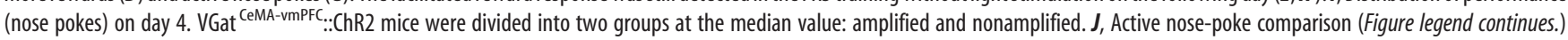




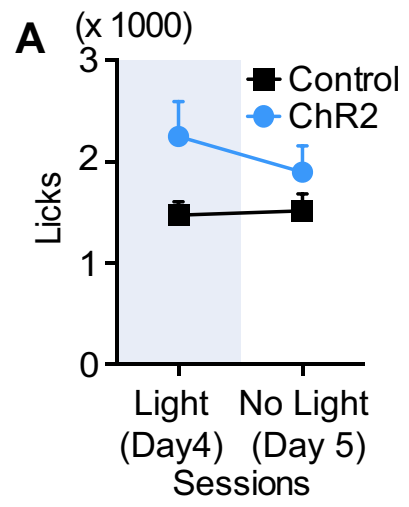

B

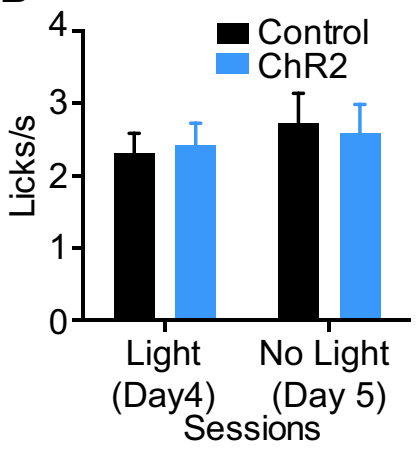

Figure 5. VGat ${ }^{\mathrm{CeMA}-\mathrm{vmPFC}}$ activation did not alter licking behavior. $\boldsymbol{A}$, Total number of licks during the training sessions. $\boldsymbol{B}$, Lick rate in total licks/rewards $/ 20 \mathrm{~s}$.

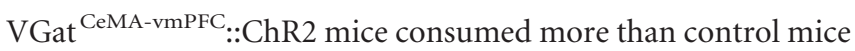
during $20 \mathrm{~s}$ sipper presentation on the FR3 + light session, but this trend was weakened in the absence of photostimulation on the FR3 + no-light session (day 5: FR3 + no light; Fig. 5A; REML: group, $F_{(1,31.58)}=4.08, p=0.051$; day, $F_{(1,30.54)}=1.03, p=0.31$; group $\times$ frequency, $F_{(1,30.54)}=1.68, p=0.204$; degree of freedom was adjusted). To assess more directly whether the photostimulation altered the licking behavior per se, we quantified the licking rate (licking rate $=$ total licks/rewards $/ 20 \mathrm{~s}$ ). No main effects of group or light or the interaction of group $\times$ light were detected (Fig. $5 B ; F<1, p>0.4$ ), suggesting that VGat ${ }^{\mathrm{CeMA}-\mathrm{vmPFC}}:$ :ChR2 activation does not alter licking behavior or generalized reward consumption.

\section{VGat-Cre ${ }^{\text {CeMA-vmPFC::ChR2 terminal photoactivation }}$ facilitates extinction of sucrose-seeking behavior}

Our previous experiments suggested that photoactivation of the VGat ${ }^{\text {CeMA-vmPFC }}$ circuit modulates external reward value rather than being inherently rewarding. Although this implication is consistent with the result of a recent study showing that CeA optogenetic activation amplified incentive salience (Robinson et al., 2014), many studies have also implicated the vmPFC in the extinction of conditioned behaviors (Peters et al., 2009; Mendoza et al., 2015). Therefore, we extended our investigation of this

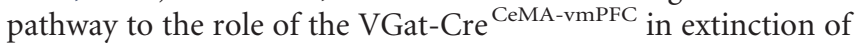
sucrose operant conditioning.

We tested whether VGat ${ }^{\mathrm{CeMA}-\mathrm{vmPFC}}:$ :ChR2 terminal activation was sufficient to modulate the extinction of sucrose operant conditioning. Operant responses on the active nose-poke portal were reinforced on an FR1 schedule with 10\% sucrose solution delivery to the sipper (Fig. $6 A, B$ ). There were no consequences for responses on the inactive portal. Mice were trained on an FR1 schedule sucrose operant conditioning paradigm for 8 consecutive days without light stimulation. The number of rewards that mice received and nose pokes were compared throughout the $8 \mathrm{~d}$ of training between the VGat ${ }^{\mathrm{CeMA}-\mathrm{vmPFC}}$ ::ChR2 group and the control group. There were no main effects of group or group $X$

$\leftarrow$

(Figure legend continued.) of the three groups (Amplified, nonamplified, and control). The amplified VGat ${ }^{\text {CeMA-vmPFC }}$ mice nose poked significantly more than other groups on day 4 $($ FR3 + light), but returned to control levels on day 5 (FR3 + no light). $\boldsymbol{K}$, Reconstruction of the approximate locations of the fiber-optic tips. $L$, Fluorescence intensity in the vmPFC, CeA, and MeA.M, Scatter graph depicting the relationship between the number of active nose pokes and vmPFC fluorescence intensity on the FR3 + light (day 4). ${ }^{*} p<0.05$. day interactions on received rewards (Fig. 6C; REML: group, $F_{(1,19)}=1.96, p=0.177$; group $\times$ Frequency, $F_{(7,133)}=0.22, p=$ 0.979 ) or active nose pokes (Fig. $6 D$; REML: group, $F_{(1,19)}=2.76$, $p=0.113$; group $\times$ frequency, $\left.F_{(7,133)}=0.04, p=1\right)$ throughout training and there was no difference in responses on the inactive lever (Fig. $6 D ; F<1$, n.s.). On the ninth day, mice were tested on the extinction procedure, wherein responses on the active portal no longer rewarded $10 \%$ sucrose and $20 \mathrm{~Hz}$ light stimulation was delivered throughout the testing session. Control mice showed increased nose pokes to the active portal compared with the last day of FR1 training because of the absence of the reward, whereas

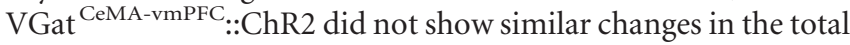
number of active nose pokes (Fig. 6D,E). Post hoc tests confirmed that control mice nose poked significantly more on the extinction day than on the last day of the training (Fig. $6 E$; control, last

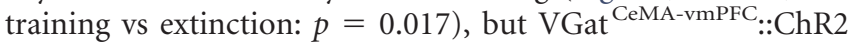
did not $(p=0.473)$. The latencies to the first visit into the active nose poke portal were not different between VGat ${ }^{\text {CeMA-vmPFC }:: C h R 2 ~ m i c e ~ a n d ~ c o n t r o l ~ m i c e ~(g r a p h ~ i s ~ n o t ~}$ shown; $t_{(19)}=-0.98, p=0.337$ ), indicating that light stimulation did not change the initial motivation to seek the reward. During extinction training, nose pokes were reduced more rap-

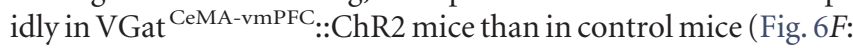
extinction; REML: group $\times$ bin, $\left.F_{(5,95)}=2.81, p=0.027\right)$. Post hoc analysis revealed that VGat CeMA-vmPFC::ChR2 mice nose poked significantly less than control mice in the first $10 \mathrm{~min}(p<$ 0.001 ), suggesting that VGat ${ }^{\mathrm{CeMA}-\mathrm{vmPFC}}$ photoactivation facilitates extinction training. On the day after extinction, mice were retrained in the extinction procedure without stimulation to test whether the reduction in nose pokes was a transient effect or long-lasting extinction learning. In the absence of photostimula-

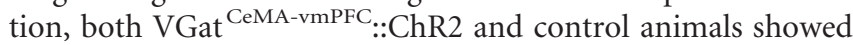
equivalent numbers of nose pokes (Fig. $6 D$ : recall; $t_{(19)}=-0.047$, $p=0.96)$. Further analysis with time bins confirmed that the number of nose pokes decreased similarly between groups throughout the recall session (Fig. 6F: recall; REML: group, $F_{(1,44.1)}=0.17, p=0.683$; bin, $F_{(5,112.1)}=7.04, p<0.0001$; group $\times$ Bin, $F_{(5,112.1)}=0.79, p=0.562$; the degree of freedom was adjusted). Importantly, there was no change in the number of nose pokes to the active portal from the last bin of the extinction day to the first bin of the nose pokes in the recall day (Fig. $6 \mathrm{~F}$; REML: group, $F_{(1,37.3)}=0.02, p=0.891$; bin, $F_{(1,36)}=3.56, p=$ 0.066 ; group $\times$ bin, $\left.F_{(1,36)}=2.42, p=0.128\right)$, suggesting that VGat ${ }^{C e M A-v m P F C}::$ ChR2 activation facilitates extinction learning of sucrose operant conditioning. Together, these data suggest that tonic stimulation of the VGat ${ }^{\text {CeMA-vmPFC }}$ circuit inhibits the nose-poke-sucrose association in sucrose extinction training and reinforces the role of the $\mathrm{vmPFC}$ in the extinction process of appetitive conditioning.

\section{Discussion}

In this study, we identified a novel GABAergic projection from the CeMA to the vmPFC and showed that the photoactivation of this VGat ${ }^{\text {CeMA-vmPFC }}$ circuit drives a preference/reward-related behavior using RTPP, OFT, and sucrose operant conditioning behavioral tasks. Photostimulation of VGat ${ }^{\text {CeMA-vmPFC }}$ terminals drove a preference for the photostimulation-paired RTPP side, indicating that this pathway elicits a positive emotional valence. Based on this, we explored the role of this VGat ${ }^{\text {CeMA-vmPFC }}$ pathway in reward-seeking behavior using a naturally positive reinforcement: sucrose. We demonstrated that the excitation of these terminals facilitates the extinction of a learned sucrose operant conditioning and, in the FR3 training, increases the nose-poking 

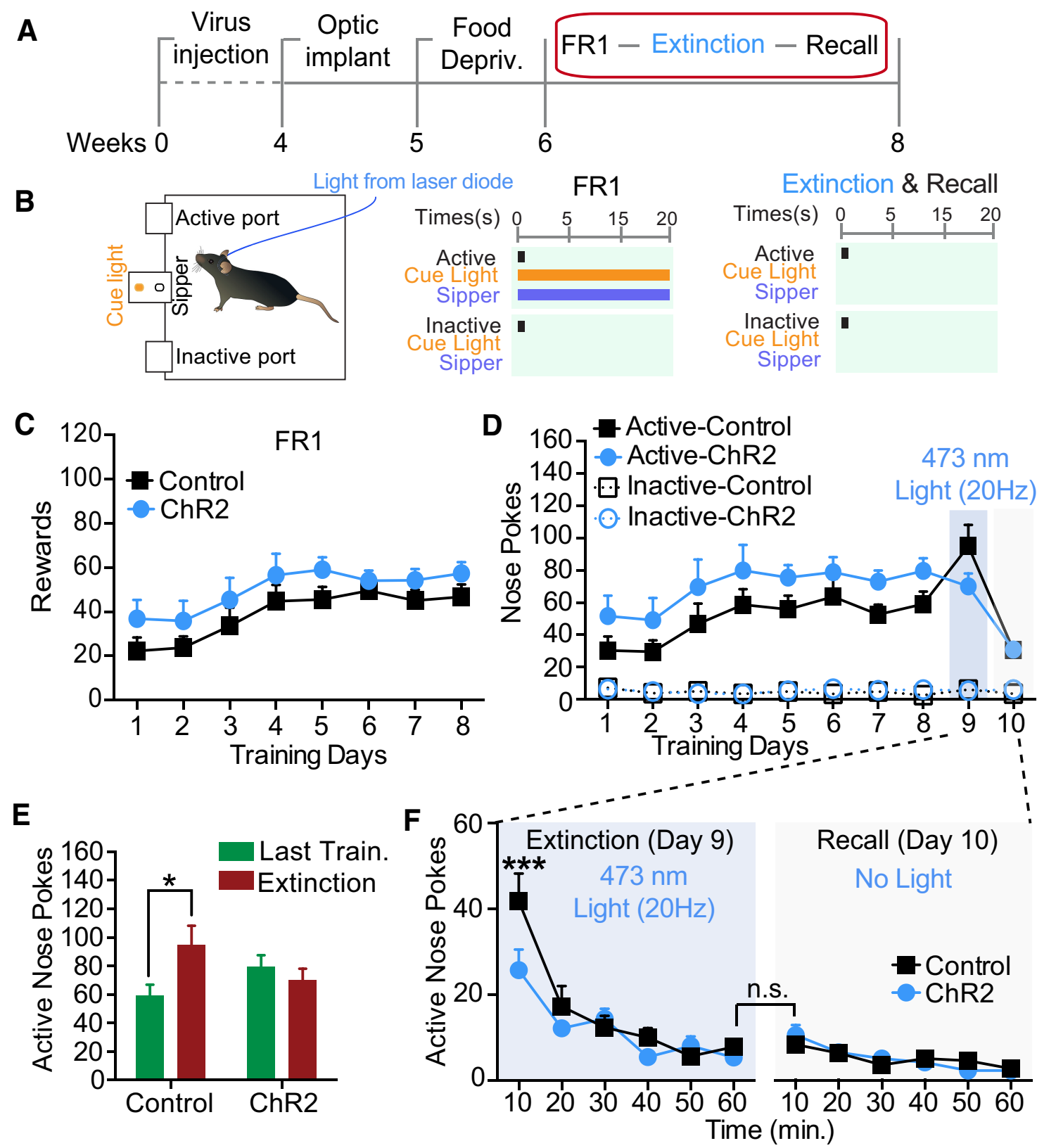

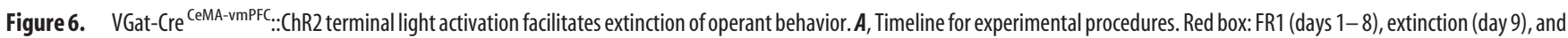
recall (day 10). Blue text represents behavioral tests performed with light stimulation. $\boldsymbol{B}$, After viral and fiber-optic delivery, mice ( $n=10-11 /$ group) were trained on the FR1 schedule sucrose operant conditioning for 8 consecutive days. Then, mice were subjected to extinction training with light stimulation throughout the session, followed by recall testing without light stimulation.

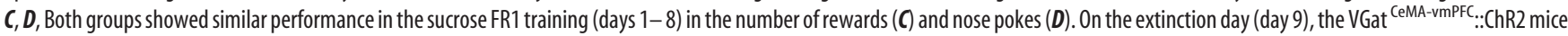
showed faster extinction compared with control mice ( $\boldsymbol{D}$, blue). $\boldsymbol{E}$, Control mice showed a significant increase in nose pokes on the extinction day compared with the last day of FR1, but

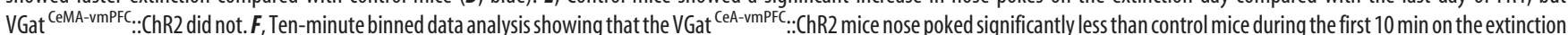
day (day 9). On the recall day (day 10), both groups showed similar level of sucrose operant performances. There were no differences between the last bin of the extinction day and first bin of the recall day in the number of active nose pokes. ${ }^{*} p<0.05,{ }^{* * *} p<0.001$.

efforts intensely to receive sucrose rewards. However, photoactivation of these terminals was not sufficient to induce selfstimulation behavior.

These behavioral patterns are consistent with a recent evidence suggesting that the CeA, but not the BLA, is involved in the amplification of external incentive value without affecting natural intrinsic motivation (Robinson et al., 2014). However, we are cautious to completely exclude the possibility that photoactivation carries an intrinsically rewarding effect because it was sufficient to drive RTPP. One possibility is that VGat CeMA-vmPFC photostimulation has a rewarding effect, but that it is not enough to drive intrinsic motivation in a more complex behavioral task that demands higher cognitive processes (exploring a chamber in RTPP vs nose poking to a specific portal associated with photoactivation). That is, although both exploring and nose poking are motivationally required actions to receive a reward, operant nose poking for a reward has more complex stages to be achieved because it requires relatively unnatural behavior compared with traveling in a testing box. This complexity makes failing to form nose-poking self-stimulation more difficult to interpret (Ito et al., 2005; Ito et al., 2008; Malkki et al., 2010). In fact, whereas there was a significant preference effect associated with 
VGat ${ }^{\text {CeMA-vmPFC }}$ photostimulation in our RTPP test, the effect size was indeed relatively small compared with other canonical reward pathway activations (Kim et al., 2013; Al-Hasani et al., 2015; Namburi et al., 2016; 57\% to photostimulation paired side at $20 \mathrm{~Hz}$ ). Conversely, exploratory behavior itself can also be interpreted as an intrinsically rewarding experience. Many species, including mice, show a natural preference for exploring novel environments and objects, which implies that the act of exploration itself has some reward value to the animal (Mench, 1998a; Mench, 1998b). It is also plausible that the reward from exploring a novel environment was amplified by VGat CeMA-vmPFC::ChR2 photoactivation and this drove the preference seen in the RTPP test. Also consistent with this possibility, VGat ${ }^{\mathrm{CeMA}-\mathrm{vmPFC}}:$ :ChR2 mice showed more exploratory behavior in the OFT experiment, another novel environmental stimulus. This activity-level change interpretation is not likely to explain the facilitation of extinction in the sucrose operant conditioning, however, because mice were already familiarized with the operant conditioning chambers (Fig. 6C,D). In extinction training, the groups of mice showed similar latency to the first visit to the active nose portal and extinction recall performance was equivalent between groups (Fig. 6D). These data support that the reduction of nose pokes is more likely to reflect facilitation of extinction learning after nose poking rather than transient motivational changes provoked by contextual cues.

At present, it is not clear whether the VGat ${ }^{\text {CeMA-vmPFC }}$ pathway has a common role in both extinction and acquisition of sucrose operant conditioning or if the VGat ${ }^{\mathrm{CeMA}-\mathrm{vmPFC}}$ pathway has a distinct role in each phase of sucrose operant conditioning. One possible explanation is that the VGat ${ }^{\mathrm{CeMA}-\mathrm{vmPFC}}$ projection may be involved in the general amplification of associations between response (R; nose poke) and outcome (O; sucrose; Robinson et al., 2014). For instance, when the nose-poke response results in no reward, VGat ${ }^{\mathrm{CeMA}-\mathrm{vmPFC}}$ activation amplifies the R-O (nose-poke-no reward) relationship and facilitates extinction. Alternatively, activation could have changed underlying motivational state of the animal and thus affected extinction performance. It has been suggested that the vmPFC plays an overall inhibitory role on behavioral states (e.g., inhibit fear, inhibit drug seeking). Because activation of the VGat ${ }^{\text {CeMA-vmPFC }}$ circuit inhibits vmPFC neurons, it is reasonable to predict an impairment of extinction learning. Instead, we found that

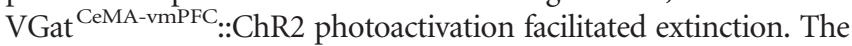
extinction-facilitating effect was somewhat puzzling, but it may reflect that VGat ${ }^{\mathrm{CeMA}-\mathrm{vmPFC}}$ activation enhances positive valence state or increased arousal level, as we found in the RTPP and OFT tests, and the altered reward-like state may affect extinction behavior. For example, the enhanced positive state caused by VGat ${ }^{\mathrm{CeMA}-\mathrm{vmPFC}}$ activation could cause the VGat ${ }^{\mathrm{CeMA}-\mathrm{vmPFC}}$ ::ChR2 mice to increase reward prediction error and facilitate extinction (Watanabe et al., 2013). However, these hypotheses require further investigation in additional studies.

The vmPFC typically has typically been identified as an inhibitor of learned fear in an aversive Pavlovian conditioning paradigm. Numerous studies have shown that lesion or pharmacological inactivation of the vmPFC results in an impairment of extinction learning using Pavlovian fear-conditioning paradigm (Morgan and LeDoux, 1995; Quirk et al., 2000). Single-unit recording studies have shown that, when vmPFC neurons are responsive to the fear tone during extinction training, animals show better extinction recall later (Milad and Quirk, 2002). In addition, electrical/optogenetical stimulation of the vmPFC facilitates the extinction learning, implying that vmPFC is involved in extinction memory and has an inhibitory role of conditioned fear
(Milad and Quirk, 2002; Do-Monte et al., 2015). In drug addiction, several studies have suggested that the vmPFC exerts inhibitory drive on drug-seeking behavior (Peters et al., 2009), with important implications in top-down control for addictive phenotypes. For example, pharmacological inactivation of the vmPFC results in the relapse (e.g., reinstatement) of extinguished cocaine-seeking behaviors, although several studies now show some contradictory results (Peters et al., 2008; LaLumiere et al., 2012; Van den Oever et al., 2013). The role of the circuit that we identified in drug addiction models (i.e., self-administration) and how the dense neuropeptidergic CeMA populations that project back to the vmPFC are involved remain to be explored. For example, the role of CeA CRF (McCall et al., 2015) and CeA dynorphin- $\kappa$ opioid-mediated drug-seeking (Al-Hasani et al., 2015) behaviors would be interesting future avenues of exploring this pathway.

Furthermore, there are relatively few reports that have evaluated the role of the vmPFC in the extinction phase of sucrose operant training, but a recent study showed that infusion of D-cycloserine, a coagonist at the NMDA receptor, into the vmPFC before sucrose operant conditioning enhanced extinction memory in rats, consistent with the idea that the vmPFC exerts inhibitory drive on drugseeking behavior (Peters and De Vries, 2013). Given the suggested inhibitory role of the vmPFC, VGat ${ }^{\mathrm{CeMA}-\mathrm{vmPFC}}$ ::ChR2 photoactivation might be expected to result in an impairment of extinction learning due to enhanced inhibitory circuit from CeMA to pyramidal cells in the vmPFC. Instead, we found that

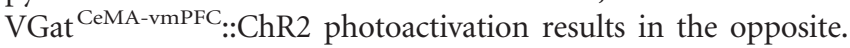
This discrepancy may imply that the extinction neural circuits of the Pavlovian fear conditioning is different from the extinction circuits of appetitive operant conditioning (Mendoza et al., 2015) or due to other training protocol differences (e.g., cue light usage in operant training) or differences in subjects (e.g., rats vs mice). Alternatively, VGat ${ }^{\mathrm{CeMA}-\mathrm{vmPFC}}:$ :ChR2 activation might inhibit a subpopulation of vmPFC pyramidal cells that are specifically involved in an appetitive condition.

We used a VGat-cre transgenic mouse line with AAV5-ChR2 virus to encode light-sensitive cation channel in the CeA. The virus expressed widely throughout anterior-posterior axis, almost covered the entire the CeA area, and, consistent with other reports, was not seen in the BLA. However, the ChR2 virus also spread sparsely into the MeA (Fig. $4 L$ ), where many GABAergic neurons are also present. We were careful to target the CeA based on well established stereotaxic coordinates in mice (Cai et al., 2014; McCall et al., 2015); however, this is a technical limitation due to close proximity and a lack of known molecular markers that adequately divide these two brain regions and this vmPFC projection. Therefore, we do not completely exclude projections from the MeA to vmPFC in the robust behaviors that we observed in this report given the retrograde labeling to MeA that we show in Figure 1. The MeA is mostly known to process olfactory information or to control copulatory behavior, which may not be as closely related to the role of the CeMA-vmPFC inhibitory circuit as we found here (Canteras et al., 1995; Keshavarzi et al., 2014). However, further studies are needed to clarify the functional distinction between the CeA- and MeA-vmPFC circuits with more sophisticated labeling techniques. Therefore, we classified our projection source as the CeMA, which includes both the CeA and MeA (Sah et al., 2003), so that follow-up reports can distinguish these subregions accurately using advanced neuronal markers (e.g., more selective Cre-driver mice).

It has been documented that the inhibitory role of the vmPFC in drug-seeking behaviors is mediated by glutamatergic inputs 
from vmPFC to the NA shell (Voorn et al., 2004). The NA shell sends GABAergic projections to the ventral pallidum, which is critical for executing motivated behaviors (Peters et al., 2009; Root et al., 2015). Conversely, a recent study identified a pathway originating in the infralimbic PFC, one subregion of the vmPFC that provides tonic inhibition to the VTA. Pharmacological inhibition of this area increases activity of the VTA and is rewarding to the animal. Similarly, excitation of this area decreases activity of the VTA and is aversive to the animal (Patton et al., 2013). We speculate that VGat ${ }^{\mathrm{CeMA} A \mathrm{vmPFC}}$ ::ChR2 activation leads to inhibition of its targets in the vmPFC through GABAergic signaling. This subpopulation of the vmPFC has been shown previously to be sufficient for reward behaviors through subsequent disinhibition of VTA dopamine neurons. Therefore, we propose that activity in this projection mediates incentive salience via a subpopulation inhibition of the vmPFC and disinhibition of the VTA. In the future, with the use of a genetically encoded calcium indicator (GCaMP), we may identify which subpopulation(s) of neurons and ensembles are involved.

The data presented here provide further evidence for involvement of the CeMA in reward behavior, which is of particular interest because the amygdala has historically been associated with fear and anxiety behaviors. Furthermore, our data build off of previous work implicating CeMA circuitry in incentive salience, but we now narrow the investigation down to a single GABAergic projection to the vmPFC, a structure previously implicated in reward behavior. Moreover, we show evidence for circuitry typically associated with emotional processing interacting directly with circuitry typically associated with cognitive processing, providing a new angle on the neurobiology of reward behavior. These results have implications for understanding the neurobiology of reward, extinction learning, and facilitation of motivation for rewards and may have important implications in understanding the neurobiology of drug abuse.

\section{References}

Adhikari A, Lerner TN, Finkelstein J, Pak S, Jennings JH, Davidson TJ, Ferenczi E, Gunaydin LA, Mirzabekov JJ, Ye L, Kim SY, Lei A, Deisseroth K (2015) Basomedial amygdala mediates top-down control of anxiety and fear. Nature 527:179-185. CrossRef Medline

Al-Hasani R, McCall JG, Shin G, Gomez AM, Schmitz GP, Bernardi JM, Pyo CO, Park SI, Marcinkiewcz CM, Crowley NA, Krashes MJ, Lowell BB, Kash TL, Rogers JA, Bruchas MR (2015) Distinct subpopulations of nucleus accumbens dynorphin neurons drive aversion and reward. Neuron 87:1063-1077. CrossRef Medline

Baxter MG, Murray EA (2002) The amygdala and reward. Nat Rev Neurosci 3:563-573. CrossRef Medline

Cai H, Haubensak W, Anthony TE, Anderson DJ (2014) Central amygdala PKC- $\delta(+)$ neurons mediate the influence of multiple anorexigenic signals. Nat Neurosci 17:1240-1248. CrossRef Medline

Canteras NS, Simerly RB, Swanson LW (1995) Organization of projections from the medial nucleus of the amygdala: a PHAL study in the rat. J Comp Neurol 360:213-245. CrossRef Medline

Cho JH, Deisseroth K, Bolshakov VY (2013) Synaptic encoding of fear extinction in mPFC-amygdala circuits. Neuron 80:1491-1507. CrossRef Medline

Davis M, Rainnie D, Cassell M (1994) Neurotransmission in the rat amygdala related to fear and anxiety. Trends Neurosci 17:208-214. CrossRef Medline

Do-Monte FH, Manzano-Nieves G, Quiñones-Laracuente K, Ramos-Medina L, Quirk GJ (2015) Revisiting the role of infralimbic cortex in fear extinction with optogenetics. J Neurosci 35:3607-3615. CrossRef Medline

Ferenczi EA, Zalocusky KA, Liston C, Grosenick L, Warden MR, Amatya D, Katovich K, Mehta H, Patenaude B, Ramakrishnan C, Kalanithi P, Etkin A, Knutson B, Glover GH, Deisseroth K (2016) Prefrontal cortical regulation of brainwide circuit dynamics and reward-related behavior. Science 351:aac9698. CrossRef Medline
Gorwood P (2008) Neurobiological mechanisms of anhedonia. Dialogues Clin Neurosci 10:291-299. Medline

Gosnell BA (1988) Involvement of mu opioid receptors in the amygdala in the control of feeding. Neuropharmacology 27:319-326. CrossRef Medline

Hikosaka O, Bromberg-Martin E, Hong S, Matsumoto M (2008) New insights on the subcortical representation of reward. Curr Opin Neurobiol 18:203-208. CrossRef Medline

Ito R, Everitt BJ, Robbins TW (2005) The hippocampus and appetitive Pavlovian conditioning: effects of excitotoxic hippocampal lesions on conditioned locomotor activity and autoshaping. Hippocampus 15:713-721. CrossRef Medline

Ito R, Robbins TW, Pennartz CM, Everitt BJ (2008) Functional interaction between the hippocampus and nucleus accumbens shell is necessary for the acquisition of appetitive spatial context conditioning. J Neurosci 28: 6950-6959. CrossRef Medline

Jackson ME, Moghaddam B (2001) Amygdala regulation of nucleus accumbens dopamine output is governed by the prefrontal cortex. J Neurosci 21:676-681. Medline

Jennings JH, Sparta DR, Stamatakis AM, Ung RL, Pleil KE, Kash TL, Stuber GD (2013) Distinct extended amygdala circuits for divergent motivational states. Nature 496:224-228. CrossRef Medline

Kelley AE, Berridge KC (2002) The neuroscience of natural rewards: relevance to addictive drugs. J Neurosci 22:3306-3311. Medline

Keshavarzi S, Sullivan RK, Ianno DJ, Sah P (2014) Functional properties and projections of neurons in the medial amygdala. J Neurosci 34:86998715. CrossRef Medline

Kim TI et al. (2013) Injectable, cellular-scale optoelectronics with applications for wireless optogenetics. Science 340:211-216. CrossRef Medline

LaLumiere RT, Smith KC, Kalivas PW (2012) Neural circuit competition in cocaine-seeking: roles of the infralimbic cortex and nucleus accumbens shell. Eur J Neurosci 35:614-622. CrossRef Medline

LeDoux JE (1993) Emotional memory: in search of systems and synapses. Ann N Y Acad Sci 702:149-157. CrossRef Medline

Lee HJ, Gallagher M, Holland PC (2010) The central amygdala projection to the substantia nigra reflects prediction error information in appetitive conditioning. Learn Mem 17:531-538. CrossRef Medline

Li X, Zeric T, Kambhampati S, Bossert JM, Shaham Y (2015) The central amygdala nucleus is critical for incubation of methamphetamine craving. Neuropsychopharmacology 40:1297-1306. CrossRef Medline

Likhtik E, Pelletier JG, Paz R, Paré D (2005) Prefrontal control of the amygdala. J Neurosci 25:7429-7437. CrossRef Medline

Malkki HA, Donga LA, de Groot SE, Battaglia FP; NeuroBSIK Mouse Phenomics Consortium, Pennartz CM (2010) Appetitive operant conditioning in mice: heritability and dissociability of training stages. Front Behav Neurosci 4:171. CrossRef Medline

McCall JG, Al-Hasani R, Siuda ER, Hong DY, Norris AJ, Ford CP, Bruchas MR (2015) CRH engagement of the locus coeruleus noradrenergic system mediates stress-induced anxiety. Neuron 87:605-620. CrossRef Medline

McDonald AJ (1987) Organization of amygdaloid projections to the mediodorsal thalamus and prefrontal cortex: a fluorescence retrograde transport study in the rat. J Comp Neurol 262:46-58. CrossRef Medline

Mench J (1998a) Why it is important to understand animal behavior. ILAR J 39:20-26. CrossRef Medline

Mench, JA (1998b) Environmental enrichment and the importance of exploratory behavior. In: Second nature: environmental enrichment for captive animals, pp 30-46. Washington, DC: Smithsonian Institution.

Mendoza J, Sanio C, Chaudhri N (2015) Inactivating the infralimbic but not prelimbic medial prefrontal cortex facilitates the extinction of appetitive Pavlovian conditioning in Long-Evans rats. Neurobiol Learn Mem 118: 198-208. CrossRef Medline

Milad MR, Quirk GJ (2002) Neurons in medial prefrontal cortex signal memory for fear extinction. Nature 420:70-74. CrossRef Medline

Morgan MA, LeDoux JE (1995) Differential contribution of dorsal and ventral medial prefrontal cortex to the acquisition and extinction of conditioned fear in rats. Behav Neurosci 109:681-688. CrossRef Medline

Namburi P, Beyeler A, Yorozu S, Calhoon GG, Halbert SA, Wichmann R, Holden SS, Mertens KL, Anahtar M, Felix-Ortiz AC, Wickersham IR, Gray JM, Tye KM (2015) A circuit mechanism for differentiating positive and negative associations. Nature 520:675-678. CrossRef Medline 
Namburi P, Al-Hasani R, Calhoon GG, Bruchas MR, Tye KM (2016) Architectural representation of valence in the limbic system. Neuropsychopharmacology 41:1697-1715. CrossRef Medline

Nieh EH, Kim SY, Namburi P, Tye KM (2013) Optogenetic dissection of neural circuits underlying emotional valence and motivated behaviors. Brain Res 1511:73-92. CrossRef Medline

Paré D, Quirk GJ, Ledoux JE (2004) New vistas on amygdala networks in conditioned fear. J Neurophysiol 92:1-9. CrossRef Medline

Parker KE, Johns HW, Floros TG, Will MJ (2014) Central amygdala opioid transmission is necessary for increased high-fat intake following $24 \mathrm{~h}$ food deprivation, but not following intra-accumbens opioid administration. Behav Brain Res 260:131-138. CrossRef Medline

Patton MH, Bizup BT, Grace AA (2013) The infralimbic cortex bidirectionally modulates mesolimbic dopamine neuron activity via distinct neural pathways. J Neurosci 33:16865-16873. CrossRef Medline

Paxinos G, Franklin KBJ (2001) The mouse brain in stereotaxic coordinates. San Diego: Academic.

Peters J, De Vries TJ (2013) D-cycloserine administered directly to infralimbic medial prefrontal cortex enhances extinction memory in sucroseseeking animals. Neuroscience 230:24-30. CrossRef Medline

Peters J, LaLumiere RT, Kalivas PW (2008) Infralimbic prefrontal cortex is responsible for inhibiting cocaine seeking in extinguished rats. J Neurosci 28:6046-6053. CrossRef Medline

Peters J, Kalivas PW, Quirk GJ (2009) Extinction circuits for fear and addiction overlap in prefrontal cortex. Learn Mem 16:279-288. CrossRef Medline

Quirk GJ, Russo GK, Barron JL, Lebron K (2000) The role of ventromedial prefrontal cortex in the recovery of extinguished fear. J Neurosci 20:62256231. Medline

Richard JM, Berridge KC (2013) Prefrontal cortex modulates desire and dread generated by nucleus accumbens glutamate disruption. Biol Psychiatry 73:360-370. CrossRef Medline

Robinson MJ, Warlow SM, Berridge KC (2014) Optogenetic excitation of central amygdala amplifies and narrows incentive motivation to pursue one reward above another. J Neurosci 34:16567-16580. CrossRef Medline

Root DH, Melendez RI, Zaborszky L, Napier TC (2015) The ventral pallidum: Subregion-specific functional anatomy and roles in motivated behaviors. Prog Neurobiol 130:29-70. CrossRef Medline
Sah P, Faber ES, Lopez De Armentia M, Power J (2003) The amygdaloid complex: anatomy and physiology. Physiol Rev 83:803-834. CrossRef Medline

Schoenbaum G, Chiba AA, Gallagher M (1998) Orbitofrontal cortex and basolateral amygdala encode expected outcomes during learning. Nat Neurosci 1:155-159. CrossRef Medline

Siuda ER, Copits BA, Schmidt MJ, Baird MA, Al-Hasani R, Planer WJ, Funderburk SC, McCall JG, Gereau RW 4th, Bruchas MR (2015) Spatiotemporal control of opioid signaling and behavior. Neuron 86:923-935. CrossRef Medline

Sparta DR, Stamatakis AM, Phillips JL, Hovelsø N, van Zessen R, Stuber GD (2012) Construction of implantable optical fibers for long-term optogenetic manipulation of neural circuits. Nat Protoc 7:12-23. Medline

Sparta DR, Hovelsø N, Mason AO, Kantak PA, Ung RL, Decot HK, Stuber GD (2014) Activation of prefrontal cortical parvalbumin interneurons facilitates extinction of reward-seeking behavior. J Neurosci 34:3699-3705. CrossRef Medline

Stuber GD, Sparta DR, Stamatakis AM, van Leeuwen WA, Hardjoprajitno JE, Cho S, Tye KM, Kempadoo KA, Zhang F, Deisseroth K, Bonci A (2011) Excitatory transmission from the amygdala to nucleus accumbens facilitates reward seeking. Nature 475:377-380. CrossRef Medline

Van den Oever MC, Rotaru DC, Heinsbroek JA, Gouwenberg Y, Deisseroth K, Stuber GD, Mansvelder HD, Smit AB (2013) Ventromedial prefrontal cortex pyramidal cells have a temporal dynamic role in recall and extinction of cocaine-associated memory. J Neurosci 33:18225-18233. CrossRef Medline

van Zessen R, Phillips JL, Budygin EA, Stuber GD (2012) Activation of VTA GABA neurons disrupts reward consumption. Neuron 73:1184-1194. CrossRef Medline

Vong L, Ye C, Yang Z, Choi B, Chua S Jr, Lowell BB (2011) Leptin action on GABAergic neurons prevents obesity and reduces inhibitory tone to POMC neurons. Neuron 71:142-154. CrossRef Medline

Voorn P, Vanderschuren LJ, Groenewegen HJ, Robbins TW, Pennartz CM (2004) Putting a spin on the dorsal-ventral divide of the striatum. Trends Neurosci 27:468-474. CrossRef Medline

Watanabe N, Sakagami M, Haruno M (2013) Reward prediction error signal enhanced by striatum-amygdala interaction explains the acceleration of probabilistic reward learning by emotion. J Neurosci 33:4487-4493. CrossRef Medline 